\title{
Reparaciones colectivas y producción de lo común: el caso del sujeto de reparación colectiva de La Sonora (Trujillo, Valle del Cauca)*
}

\author{
MARÍA FERNANDA SAÑUdO** \\ DANNA CAROLINA AgUILAR*** \\ SARA ALEJANDRA LEÓN ${ }^{\dagger}$ \\ CHRISTOPHER ZAHONERO ${ }^{\text {H }}$ \\ LUCAS PÉREZ SOTO
}

Artículo recibido: 31 de octubre de 2019

Artículo aprobado: 16 de mayo de 2020

Doi: https://doi.org/10.12804/revistas.urosario.edu.co/desafios/a.8405

* Este artículo corresponde a uno de los resultados alcanzados en el marco del desarrollo del proyecto "Restitución de tierras y espacialidades capitalistas", financiado por la Vicerrectoría de Investigación de la Pontificia Universidad Javeriana.

** Docente e investigadora, Instituto Pensar, Pontificia Universidad Javeriana; coordinadora del grupo de trabajo del Clacso "Desarrollo, políticas públicas y desigualdades territoriales”. Correo electrónico: msanudo@javeriana.edu.co. ORCID: https://orcid. org/0000-0002-5717-9297

*** Coordinadora semillero de investigación "Aproximaciones críticas al análisis de las políticas públicas”, Instituto Pensar, Pontificia Universidad Javeriana. Correo electrónico: dcagular@unal.edu.co. ORCID: https://orcid.org/0000-0003-1654-2309

† Investigadora del semillero "Aproximaciones críticas al análisis de las políticas públicas", Instituto Pensar, Pontificia Universidad Javeriana. Correo electrónico: sara.leon@javeriana. edu.co. ORCID: https://orcid.org/0000-0002-1619-5717

\# Joven investigador grupo de trabajo del Clacso "Desarrollo, política pública y desigualdades territoriales”. Correo electrónico: christopher_zb@hotmail.com. ORCID: https:// orcid.org/0000-0003-4165-4310

Ht Joven investigador grupo de trabajo del Clacso "Desarrollo, política pública y desigualdades territoriales”. Correo electrónico: lucasperso13@gmail.com. ORCID: https://orcid. org/0000-0002-1924-297X 
Para citar este artículo: Sañudo, M. F., Aguilar, D. C., León, S. A., Zahonero, C., \& Pérez Soto, L. (2021). Reparaciones colectivas y producción de lo común: el caso del sujeto de reparación colectiva de La Sonora (Trujillo, Valle del Cauca). Desafíos, 33(2), 1-36. https:// doi.org/10.12804/revistas.urosario.edu.co/desafios/a.8405

\title{
Resumen
}

En las zonas rurales de Colombia, las dinámicas complejas asociadas al conflicto armado impactaron negativamente los vínculos y relaciones sociales, las prácticas $y$ los procesos organizativos comunitarios, las tradiciones y trayectorias colectivas. El Estado colombiano ha becho frente a estos impactos a través de la reparación colectiva. Esta se constituye en un conjunto de estrategias encaminadas a reconstruir el sentido colectivo de comunidades, organizaciones y grupos que han enfrentado la violación sistemática de sus derechos. La reparación, dada su naturaleza (colectiva), está posibilitando la generación de espacios y formas de cooperación social encaminados a la reproducción simbólica y material de la vida, es decir, de producción de lo común. En este sentido y a partir de la comprensión etnográfica del proceso de reparación colectiva realizado en La Sonora (Trujillo, Valle del Cauca), se evidenciará cómo las estrategias implementadas en el territorio operan en la constitución de las condiciones para la producción y reproducción social de la vida.

Palabras clave: reparaciones colectivas; comunes; comunalización; justicia transicional; conflicto armado; Colombia; Cauca.

\section{Collective Reparations and Production of the Common: The Case of La Sonora (Trujillo, Valle del Cauca)}

\begin{abstract}
In rural areas of Colombia, the complex dynamics associated with the armed conflict negatively impacted social ties and relationships, community organizing practices and processes, traditions as well as collective trajectories. The Colombian State has dealt with these impacts through collective reparation; namely, a set of strategies aimed at reconstructing the collective meaning of communities, organizations and groups that have faced the systematic violation of their rights. Given its (collective) nature, reparation makes possible the generation of spaces and forms of social cooperation
\end{abstract}


aimed at the symbolic and material reproduction of life, that is, of processes of production of the common. We explore the collective reparation process carried out in the municipality of Trujillo (Valle del Cauca) through an ethnographic approach. The in-depth understanding of this process shows how the strategies implemented in the territory operate in the constitution of conditions for the production and reproduction of social life.

Keywords: Collective reparation; common; communing; armed conflict; transitional justice; Colombia; Cauca.

\section{Reparações coletivas e a produção do comum: o caso do sujeito da reparação coletiva de La Sonora (Trujillo, Valle del Cauca)}

\section{Resumo}

Nas áreas rurais da Colômbia, a dinâmica complexa associada ao conflito armado impactou negativamente os laços e relacionamentos sociais, as práticas e processos organizacionais da comunidade, as tradições e as trajetórias coletivas. O Estado colombiano tem enfrentado esses impactos por meio da reparação coletiva. Esta se constitui em um conjunto de estratégias voltadas para a reconstrução do sentido coletivo das comunidades, organizações e grupos que têm enfrentado a violação sistemática de seus direitos. Devido a se caráter (coletivo), a reparação está possibilitando a geração de espaços e formas de cooperação social voltadas para a reprodução simbólica e material da vida, ou seja, a produção do comum. Nesse sentido e a partir da compreensão do processo de reparação coletiva realizado em Sonora (Trujillo, Valle del Cauca), se evidenciará como as estratégias implementadas no território operam na constituição das condições para a produção e reprodução social da vida.

Palavras-chave: reparações coletivas; comuns; comunalização; justiça transicional; conflito armado; Colômbia; Cauca.

\section{Introducción}

El municipio de Trujillo por más de dos décadas se constituyó en escenario de la convergencia de múltiples violencias y de "la repetida vulneración de los derechos de las víctimas por parte de numerosos 
actores, incluido el Estado" (CNRR, 2008, p. 25). La UARIV (2014) reconoce que el despliegue de las violencias contra los habitantes tanto del casco urbano como de las zonas rurales (principalmente de las veredas El Tabor y La Sonora y los corregimientos Betulia y Maracaibo) ocasionó daños importantes en la dimensión colectiva. Esta instancia sugiere como principales impactos: el debilitamiento organizativo, las limitaciones en el desarrollo de prácticas comunitarias (sociales y económicas), la restricción de los procesos de participación y de representatividad; además, el control territorial que ejercieron los armados condicionó la movilidad de las personas y transformó la relación de las comunidades con el territorio (UARIV, 2014). Sobre las transformaciones territoriales en el contexto del conflicto armado se dio cuenta en un artículo previamente publicado (Sañudo et al., 2016).

A nuestro modo de ver, las pérdidas en esta dimensión (colectiva) deben analizarse en función de las particularidades que lo colectivo adoptó en la zona de estudio. Previo a la escalada de la guerra, los procesos organizativos y comunitarios campesinos se constituyeron en ejes de las dinámicas sociales, políticas, económicas y culturales del territorio. Estos se configuraron en relación con una tríada de factores: ${ }^{1}$ 1) la constitución de un ethos comunal como producto de los procesos de ocupación y apropiación del territorio; ${ }^{2}$ 2) los procesos de extensión rural impulsados por el Comité Municipal de Cafeteros; y 3) la formación y el fortalecimiento organizativo del campesinado a través del acompañamiento de la Iglesia católica y de organizaciones campesinas como la Federación Agraria Nacional (Fanal) y la Asociación Nacional de Usuarios Campesinos (ANUC). Estos factores coadyuvaron a la "configuración o emergencia de espacios y formas de cooperación social, de uso y goce común" (Svampa \& Viale, 2014, p. 374), y dieron lugar a formas colectivas de ser y

hacer donde el ser en común se privilegiaba sobre el ser individual

\footnotetext{
1 Sobre estos explicaremos en detalle más adelante.

2 Esto es lo que Linsalata (2015) ha denominado como ethos comunal: "Modo de concebir y organizar la vida social, una dinámica de producción y reproducción de lo común que opera en distintos espacios y tiempos".
} 
(Sañudo \& Aguilar, 2018). En este sentido, las pérdidas en el plano de lo colectivo asociadas al conflicto no solo corresponden al debilitamiento de las prácticas comunitarias o a la desestructuración de lo organizativo. De acuerdo con el caso de estudio, estas están conectadas con el deterioro profundo de las relaciones sociales de cooperación, colaboración, reciprocidad y compartencia, claves en la producción, cuidado, gestión y reproducción material y simbólica de la vida social.

El Estado colombiano encara este tipo de daños a partir de la reparación colectiva. ${ }^{3}$ Esta apunta a la reconstrucción del proyecto de vida colectivo, a la recuperación y el restablecimiento del tejido social, al fortalecimiento de las capacidades políticas de los colectivos, entre otros (UARIV, 2014). En las veredas La Sonora y El Tabor (Trujillo, Valle del Cauca), se da inicio a este proceso en 2014, año en que la Unidad para la Atención y Reparación Integral a las Víctimas (UARIV) reconoció a las comunidades que habitan este territorio como sujeto de reparación colectiva, dada la envergadura de los impactos del conflicto armado en la dimensión comunitaria. Desde esta fecha y hasta 2019 se implementaron una serie de acciones, las que identificadas y plasmadas en el Plan Integral de Reparación Colectiva ${ }^{4}$ tuvieron el propósito de resarcir el daño colectivo que emerge de la violación sistemática de los derechos humanos de los habitantes de este territorio.

En el marco de este artículo, ponemos el énfasis en analizar una de las acciones correspondiente a la medida de restitución: la creación y

3 Con base en lo estipulado en la Ley 1448 de 2011 y en el Decreto Reglamentario 4800 de 2011, se crea el Programa Administrativo de Reparación Colectiva, con el objeto de reconocer y atender los impactos del conflicto armado en la dimensión colectiva de comunidades campesinas y barriales, comunidades y pueblos étnicos, organizaciones, grupos y movimientos sociales.

4 La Ruta de Reparación Colectiva se encuentra estructurada por las siguientes etapas: 1) identificación del sujeto de reparación colectiva; 2) alistamiento comunitario e institucional; 3) diagnóstico del daño; 4) construcción del Plan Integral de Reparación Colectiva (PIRC); 5) implementación del PIRC; 6) evaluación del proceso. Específicamente frente al PIRC, este se concibe como un conjunto de acciones ancladas a las medidas de restitución, rehabilitación, satisfacción, garantías de no repetición e indemnización en los componentes social, político y económico. 
puesta en marcha de la Cooperativa Integral de Mujeres y Hombres Empresarias Agropecuarias Víctimas del Conflicto Armado de Trujillo (Cimevat). Esta tiene por objeto "recuperar y fortalecer las dinámicas comunitarias así como los espacios de encuentro para el desarrollo de actividades propias del colectivo" (UARIV, 2014). A nuestro modo de ver, la cooperativa está posibilitando, por un lado, la reactualización del ethos comunal y de los aprendizajes en el seno de los procesos organizativos campesinos de la década de los ochenta y previos a esta; y, por otro, a través de la resignificación y apropiación de los discursos y prácticas institucionales en torno a la reparación colectiva está dando lugar a las condiciones para que se inicien o reinicien procesos encaminados a "conservar, cuidar, amplificar o reapropiarse de las condiciones materiales y simbólicas necesarias para garantizar la reproducción material y simbólica de la vida" (Gutiérrez, 2017, p. 24); se constituyan o reconstituyan las tramas comunitarias (Gutiérrez \& Salazar, 2015); y se disuelvan las relaciones de mando jerárquicas, verticales y privadas (Holloway, 2011). Y es precisamente en estos aspectos que ponemos el foco del análisis. En este sentido, a lo largo de este artículo, evidenciaremos cómo el proceso Cimevat puede ser entendido como lo que Gutiérrez (2017) y Holloway (2011) han llamado "condiciones de posibilidad del hacer", ${ }^{5} \mathrm{y}$, por otro lado, está produciendo lo común, es decir, está generando o regenerando los vínculos, las tramas comunitarias, los espacios y formas de construir en colectivo las decisiones y los modos de hacer y ser.

Metodológicamente, esta investigación acoge a la etnografía como enfoque, dado que nos interesó fundamentalmente comprender los procesos de producción de lo común desde la perspectiva de los actores. Particularmente pusimos la atención en la conexión que se establece entre las prácticas y los significados que encarnan quienes integran Cimevat frente a lo colectivo, lo comunitario, el trabajo comunitario, las decisiones colectivas, la redistribución de las ganancias, la riqueza social, entre otros aspectos. Específicamente, mediante observación participante y de entrevistas en profundidad a infor-

\footnotetext{
Sobre este aspecto volveremos en profundidad en el aparte dedicado al desarrollo de los conceptos.
} 
mantes clave, nos aproximamos a cómo Cimevat está permitiendo la emergencia de "valores, pensamientos, afectos, deliberación, reglas, institucionalidad compartida y, consecuentemente, alguna forma de comunidad que lo resguarda del lucro individual y se sitúa por fuera del régimen privado de propiedad" (Vega, 2019). ${ }^{6}$ Como parte de la etnografía, se realizaron además ejercicios de memoria con el objetivo de visibilizar las tramas comunitarias que se produjeron en el pasado y cómo estas fueron afectadas por las violencias; esto contribuyó a la toma de conciencia sobre cómo algunos elementos de estas perviven (solidaridad, reciprocidad, espacios de cuidado) y sirven de anclaje para la configuración y reconfiguración de nuevos entramados colectivos en el marco del escenario transicional; recordar lo que fuimos en 'común' contribuye a crear y recrear lo que en 'común somos hoy'.

\section{Una breve aproximación al contexto}

Como ya se ha mencionado, el estudio se llevó a cabo en el municipio de Trujillo (Valle del Cauca), específicamente con las personas vinculadas al sujeto de reparación colectiva de La Sonora (el que incluye la vereda El Tabor y los corregimientos Betulia y Maracaibo). Esta zona está ubicada al noroccidente del casco urbano municipal y tiene como eje de su economía la producción de café principalmente.

El sujeto de reparación colectiva de La Sonora incluye 165 familias, quienes se reconocen como una comunidad en la medida en que "comparten una identidad derivada de compartir tradicionalmente un territorio, costumbres, reconocimiento social, una historia, entre

\footnotetext{
${ }_{6}$ Consideramos que las reflexiones aquí plasmadas pueden contribuir en dos niveles. En primer lugar, la lectura que hacemos sobre los impactos colectivos de la guerra, desde las propuestas de quienes han conceptuado sobre los comunes, contribuye a complejizar la noción de 'daño colectivo'. Esta es central a la reparación colectiva y, si bien se ha realizado un importante esfuerzo por ir más allá de lo jurídico, resulta clave una mirada interdisciplinar, mediante la que sea factible comprender su complejidad. En segundo lugar, pensar en la potencia de las prácticas de la reparación colectiva como condiciones de posibilidad del hacer común ayuda a fundamentar el potencial transformador que les ha sido reconocido a las medidas de justicia transicional.
} 
Otros" (UARIV, 2014, p. 1). Es importante destacar que muchas de estas familias están unidas por lazos de parentesco y consanguinidad; y, además, han ocupado el territorio desde mediados del siglo pasado estructurando una identidad compartida en torno a la producción de café, a la participación en procesos comunitarios de diferente índole (cooperativas, grupos de amistad, organizaciones campesinas) y el desarrollo de una serie de actividades del mismo carácter que cohesionaban a la comunidad (tiendas comunitarias, por ejemplo); también su identidad se configura en torno a la vivencia en colectivo del conflicto armado (León, 2018).

A través de la Resolución 446985 del 5 de mayo de 2014, las familias habitantes de La Sonora, El Tabor, Betulia y Maracaibo fueron reconocidas como sujeto de reparación colectiva, dada la serie de victimizaciones que vivieron entre 1986 y 2012 (desapariciones forzadas, asesinatos selectivos, desplazamiento forzado, tortura de líderes, reclutamientos forzados, confinamiento). En el marco de esta resolución, además, se relacionan las victimizaciones con los impactos sobre la dimensión colectiva. Como principales afectaciones se establecieron: "restricciones a la vida organizativa, impedimento y limitaciones en la realización de las prácticas colectivas, daños a la propiedad colectiva", entre otras (UARIV, 2014, p. 1).

\section{Tejiendo conceptualmente en torno a la 'producción de lo común'}

Gutiérrez y Salazar (2015, p. 15) definen lo "común” o los “comunes" como el "conjunto de actividades colectivas y/o comunitarias destinadas a garantizar la reproducción material y simbólica de la vida social". Estos corresponden a la serie de acciones colectivas para producir, cuidar y disfrutar de la riqueza común (riqueza social), en calidad de "valor de uso", instituyéndose por las diversas prácticas sociales para "producir y reproducir formas de habitar el mundo desde otro lugar que no es el de la dominación, la explotación y el despojo” (p. 17). 
Gutiérrez, Navarro y Linsalata (2016, p. 378) reconocen que estos corresponden al "conjunto de procesos, relaciones sociales y formas políticas que sostienen la reproducción de la vida" y en la cotidianidad se construyen para superar la "socialidad humana en función de la valorización del capital". En esta perspectiva, Caffetnzis y Federici (2015) hablan de escenarios en los cuales colectivamente es posible "contrarrestar los procesos de cercamiento a la reproducción de la vida" (p. 67).

Lo común produce, se nutre e integra lo comunitario. Gutiérrez y Salazar (2015) conciben a este como la serie de modos mediante los que se establecen, organizan, las relaciones sociales de cooperación y compartencia; son los vínculos y haceres compartidos que están anclados a la relación de un colectivo específico con el territorio que habita. Bajo esta lógica, Linsalata (2015) concibe lo comunitario como las prácticas de organización de la vida colectiva, las que son particulares y concretas en relación con el contexto en el que emergen, constituyéndose en "lógicas contemporáneas y multiformes de configuración de la vida social” (p. 22).

La autora sugiere considerar tres elementos clave en cuanto a lo comunitario. El primero es la contemporaneidad de las prácticas de organización de la vida colectiva y de "su existencia múltiple y variada en el presente" (p. 23). El segundo tiene que ver con su potencial transformador. Dado que su permanencia está imbricada con formas de luchas y resistencia posibilitan "otras formas de relacionarse y concebir el mundo" (p. 24), dan lugar a rupturas con relaciones sociales de dominación (de clase, género, raciales) mediante la "actualización y la constante producción de formas de socialidad propias y diversas" (p. 25). En tercer lugar, Linsalata se refiere a la fragilidad de lo comunitario. Este rasgo tiene que ver con las tensiones y contradicciones que emergen "del encuentro de lo común con la lógica estructurante del capital” (Gutiérrez \& Salazar, 2015, p. 16).

En la producción de lo comunitario resultan fundamentales los encuentros. Tal como afirma De Angelis (2003, p. 5), estos posibilitan la intersección de los mundos de la vida, y es en esta intersección 
que nos hacemos y rehacemos como sujetos sociales; posibilitan la interiorización de las prácticas sociales constitutivas; además, en este proceso tiene lugar el reconocimiento de los otros (Esteba \& Guerrero, 2018, p. 34). Con este "viene un intercambio de experiencias, herramientas y saberes", y se va configurando "un Nosotros y/o con las Otras/os". Así "lo comunal no es un conjunto de cosas, sino un fluir integral de posiciones de sujetos" (p. 34) y es en ese fluir que se materializa lo comunitario.

A estos vínculos Gutiérrez y Salazar (2015) los han llamado “entramados comunitarios" y se conciben como "tramas, abigarradas y complejas de relaciones sociales" (p. 20), las que, para Navarro (2013, p. 107), corresponden al "tejido que va haciendo posible lo común". Estas tramas se componen del encuentro de posiciones de sujeto, configurándose como "una específica subjetividad colectiva en marcha" (Gutiérrez, 2017, p. 68), con la capacidad de generar las condiciones para: i) la reproducción material y simbólica de la vida colectiva; y ii) la perdurabilidad y equilibrio de los vínculos producidos" entre las posiciones de sujeto (p. 68).

Estas son "creaciones colectivas plásticas y diversas", en el marco de las cuales se producen "vínculos estables y capaces de conservarse, ajustando y equilibrando, formas de autorregulación que sostengan su existencia en el tiempo" (p. 69). Particularmente Gutiérrez los define como "una heterogénea multiplicidad de mundos de la vida que pueblan y generan el mundo bajo pautas diversas de respeto, colaboración, dignidad y reciprocidad no exentas de tensión, y acosadas, sistemáticamente, por el capital” (p. 34).

El entramado comunitario, en palabras de Caffentzis y Federici (2015), sostiene la producción de la riqueza social, es decir, de un conjunto de elementos materiales, sociales, culturales o simbólicos que los sujetos, de manera colectiva y bajo parámetros de compartencia, usufructúan

\footnotetext{
Sin embargo, para Navarro (2013, p. 107), estas tramas comunitarias no están del todo subsumidas al capital, cuestión que implica la existencia de otras lógicas, las que "tendencialmente optan por el valor de uso, buscando garantizar de forma prioritaria el sustento".
} 
para el bien colectivo. La riqueza social se produce en comunidad y por eso existe. Cordero (2018) señala que esta alude "al conjunto de las capacidades colectivas de hombres y mujeres para reproducir la vida social"" (p. 230).

La producción, conservación, reproducción o reapropiación de la riqueza social es un proceso demarcado por lo que Gutiérrez (2017) ha denominado "lógicas de producción de lo común". Estas son "heterogéneas y multiformes" y se ponen en marcha en la cotidianidad con el objetivo de conservar y cuidar "los recursos materiales colectivamente disponibles" (p. 68). Entre otros serían rasgos de este tipo de lógicas: la existencia de escenarios asamblearios, de deliberación, en los que, además de la existencia de mecanismos para que la mayoría acceda a la palabra y participe activamente en la toma de decisiones, se definan los objetivos por alcanzar y las acciones para ello (Navarro, 2013).

Es factible adicionar a la comprensión de las lógicas de producción de lo común otros rasgos: la existencia de normas consuetudinarias que guían el uso y cuidado de la riqueza social que se comparte; el acceso igualitario a esta y a los beneficios que se desprenden de su gestión colectiva; y "reciprocidad entre lo que se da y lo que se toma" (Caffentzis \& Federici, 2015, p. 69).

\section{Relación conceptual entre reparación colectiva y producción de lo común}

La UARIV (2014) define la reparación colectiva como un conjunto de estrategias que están encaminadas "al reconocimiento y la dignificación de organizaciones sociales y políticas, grupos y comunidades que han sufrido un daño colectivo" (p. 16). El daño colectivo se constituye en central a esta modalidad de resarcimiento. Este se define como las

\footnotetext{
8 Tanto los recursos como las capacidades están permanentemente acechadas por el capital. Así todo lo que colectivamente se ha definido y puesto al servicio de lo común "entra en tensión con lógicas de apropiación con fines de acumulación” (Cordero, 2018, p. 231).
} 
"afectaciones negativas en el contexto social, comunitario o cultural que, a causa del conflicto armado, sufren las comunidades, grupos u organizaciones y que tienen formas vigentes de sufrimiento o afectación" (p. 17). Bajo esta lógica, se entiende que el daño es producido por la conjunción de diversas formas de victimización, las que de manera continua afectaron negativamente a una organización, comunidad o a un grupo, es decir, transformaron violentamente aquellos referentes, aspectos, elementos que mantienen la cohesión del colectivo o que le dan sentido a su proyecto común. ${ }^{9}$

Proponemos tejer la relación conceptual entre reparación colectiva y producción de lo común a partir de lo que Gutiérrez (2017) y Holloway (2011) han nombrado como "condición de posibilidad del hacer". Es decir, la serie de condiciones materiales y simbólicas que se instituye en un momento y espacio determinado para la producción de lo común. En relación con lo anterior, proponemos comprender la reparación colectiva como "condición de posibilidad del hacer" en función de cinco elementos, relacionados entre sí.

El primero de estos corresponde a los encuentros. En el marco de la Ruta de Reparación Colectiva, en todas las etapas se propicia la constitución de espacios de encuentro entre quienes se han reconocido como parte del sujeto de reparación colectiva. En estos espacios es posible el redescubrimiento del nosotros. Un nosotros en latencia. Los encuentros, además, de acuerdo con Gutiérrez (2017), posibilitan la emergencia del sentido de inclusión colectiva, aspecto que existe porque en conjunto se define un propósito o fin comunal. Así, "se deliberan y se ensayan, entonces, formas de producir colectivamente la relación 'ser parte', no a partir de códigos o términos de exclusión

\footnotetext{
$9 \quad$ En el marco del Decreto Reglamentario 4800 de 2011, se definen los objetivos del resarcimiento colectivo. Entre estos se encuentran: reconocer y dignificar a las víctimas, recuperar el tejido psicosocial, promover y posibilitar la inclusión ciudadana, reconstituir el tejido social y la confianza en el Estado (Congreso de la República de Colombia, 2011). Adicionalmente, la norma referida se constituye en la columna del Programa Institucional de Reparación Colectiva (PIRC), mediante el cual se viabilizan los objetivos planteados en el decreto (OIM, 2012). Además, establece el andamiaje que soporta el 'Modelo de Reparación Colectiva'.
} 
sino de algún sentido de inclusión” (p. 123). Con la constitución o reconstitución de un nosotros, se instituyen reglas y normas para el hacer en común y también para 'regular los conflictos internos' y sortear los problemas que como 'común' emergen y se tienen que enfrentar.

Como resultado de los encuentros, los que son posibles por la búsqueda de un fin común, se produce lo que Linsalata $(2015$, p. 73 ) ha denominado "socialidades comunitarias", es decir, formas de cohesión social que se ensayan para avanzar colectivamente hacia el propósito fijado; conforme con la autora, estas se anclan o se tejen con y en los lazos de parentesco o de afinidad que se han establecido en el territorio. Recogen y rehacen los vínculos históricos que devienen o intersectan los vínculos sociales.

El segundo elemento, que, aunque relacionado con el anterior, es diferente, corresponde a la instauración de espacios de deliberación y toma de decisiones. Los procesos de reparación colectiva apuntan a la recuperación de los procesos de participación y representatividad perdidos o debilitados como resultado de las dinámicas de la guerra. Bajo esta lógica se promueve la conformación de asociaciones, cooperativas o cualquier otro formato de organización comunitaria, en el marco de las cuales resulta fundamental la institucionalización de espacios y de mecanismos para la participación amplia e igualitaria en la toma de decisiones. Así la reparación colectiva produce el hacer común en relación con la toma de decisión y con la constitución de acuerdos para alcanzar el propósito común.

La implementación de las medidas de la reparación colectiva tiene como componente principal el trabajo comunitario, el que consideramos como tercer elemento. Zibechi (2015) reconoce a este como una de las condiciones para la producción de los comunes. Dice el autor que son los "trabajos colectivos los que le dan vida, sentido, forma y fondo al hecho comunal" (p. 75). Trabajar en conjunto, con un fin concreto, teje y entreteje las tramas comunitarias. Mediante el trabajo comunitario no solo se resuelven los problemas puntuales de una comunidad, también se refuerza "el sentimiento 
colectivo" (p. 77) y se conserva y resguarda aquello que es producido en común (Gutiérrez \& Salazar, 2015).

Un cuarto elemento corresponde al objetivo que se fija la reparación colectiva de reconstruir los procesos y trayectorias organizativas que el sujeto de reparación colectiva perdió como causa de la guerra. Al respecto plantea Gutiérrez (2017, p. 31): "Las formas asociativas casi nunca consisten en novedades plenas sino que, por lo general, se suelen recuperar, conservando y transformando, las tradiciones locales en las cuales quienes luchan han sido formados y de donde casi siempre brotan sus capacidades tanto de creación como de insubordinación, adecuándolas, expandiéndolas o perfeccionándolas para los propósitos que persiguen". En este sentido las acciones de reparación colectiva encaminadas a la recuperación de lo político están reactualizando las tramas políticas y de gestión, antes fundadas en el territorio.

Por último, el quinto elemento, dado el carácter colectivo de la reparación y en relación con los encuentros que propicia esta, está coadyuvando a la producción o reproducción de lo que Gutiérrez (2017) ha denominado "entramados comunitarios", es decir, "múltiples acciones y saberes cooperativos que anidan en las más íntimas e inmediatas relaciones de producción de la existencia cotidiana" (p. 36). Estas tramas se componen de lazos más o menos estables de cooperación o "compartencia" que se construyen y se reconstruyen a lo largo del curso de la vida colectiva; y que no están plenamente sujetas a las lógicas de acumulación de valor capitalista ni tampoco exentas de tensión (Gutiérrez, 2018). Estas tramas se sitúan en la base de la producción de lo común, que no es sino lo "producido, construido y logrado por la articulación y el esfuerzo común de hombres y mujeres situados histórica y geográficamente" (p. 45), con el objetivo de sostener "material y simbólicamente la reproducción de la vida social". 


\section{La configuración y reconfiguración en la producción de lo común en La Sonora}

\section{Organización y tramas comunitarias}

En el municipio de Trujillo previo a la escalada de la guerra los procesos organizativos y comunitarios campesinos se constituyeron en eje importante de las dinámicas del territorio. Estos se fueron configurando con relación a tres factores (interdependientes). En primer lugar, la presencia de "un sentido colectivo de la existencia", al que Linsalata (2015, p. 7) ha denominado "ethos comunal". Bajo la perspectiva de esta investigación este 'ethos' se configuró en relación con las dinámicas de ocupación del territorio. Desde los años treinta a la zona arribaron familias campesinas, las que desarrollaron como actividad principal productiva la caficultura de ladera y montaña. Consideramos que tanto la ocupación del territorio como el desarrollo de esta actividad se constituyeron en condiciones para la creación y recreación de lo 'comunitario'. Algunos de los mayores que fueron entrevistados recuerdan que sus padres y abuelos constantemente aludían a la difícil llegada al territorio y para adaptarse resultó clave la constitución de redes de vecinos y amigos. Las redes se entretejieron en torno a un objetivo común: facilitar la supervivencia en un entorno complicado, además de cooperar en lo concerniente a la producción del café.

En este contexto las mingas fueron un recurso colectivo para "construir obras de infraestructura" (p. 3). Este formato de trabajo comunitario está asociado a los orígenes de la organización comunitaria en la zona. Lo fundamental fue el trabajo compartido y solidario, con el fin de avanzar en el bienestar del colectivo. En este sentido, otra de las formas de cooperación que recuerdan los mayores corresponde a la mano vuelta. En ocasiones la falta de trabajadores impedía la realización de mejoras en las fincas. El prestar y devolver trabajo se emplazó como una estrategia social y económica fundamental. En este contexto se dio la mutua colaboración para la preparación de 
tierras, el abono y la cosecha del café. Así, lo comunitario se entretejió en el 'dar y recibir trabajo'. La reciprocidad fue fundamental para tramar las redes sociales.

Otro aspecto importante, sobre el que se destacó en las entrevistas, es la existencia de 'lugares' en el territorio para el usufructo comunal. Bosques, ríos, nacimientos de agua, entre otros, se emplazaron como espacios para el suministro de recursos comunales. El acceso a estos ocasionó una serie de conflictos, los que fueron dirimidos a través de regulaciones para la explotación de recursos. Así lo recuerda uno de los entrevistados: "Mi abuelo me decía que había lo que ellos llamaban el monte, allá podían andar todos y cazar el guatín, la danta, el venado, sacar la madera para construir, cocinar [...] él decía que a veces había problemas porque unos sacaban más que otros y entonces salían las rabias y las peleas. Tocó organizar eso, él decía que pusieron reglas para sacar la madera y cazar" (comunicación personal, La Sonora, 2018).

Con respecto a lo anterior y de acuerdo con Gutiérrez (2018, p. 35), tanto las formas de trabajo colectivo como el acceso y control comunal de los recursos compartidos crearon y recrearon los vínculos comunitarios "entre quienes comparten una trama comunitaria y a la vez, pertenecen a ella".

El segundo factor fue el papel jugado por el Comité de Cafeteros. Desde la década de los sesenta los vacíos estatales en el territorio fueron ocupados por dicha institución. Esta orientó y reguló las prácticas productivas alrededor del grano, contribuyendo tanto a la dinamización de la producción como también al desarrollo de infraestructura y el acceso a servicios sociales como vivienda, alcantarillado, educación y salud. ${ }^{10}$ En cuanto al papel de esta instancia en la potenciación de procesos organizativos, es en la década de los

\footnotetext{
10 Esta instancia, hasta finales de la década de los ochenta, contribuyó al sostenimiento de precios del café, aseguró la compra del producto, llevó a cabo procesos de transferencia de tecnología, facilitó el acceso a créditos subsidiados y a mecanismos de refinanciación de las deudas.
} 
setenta que los comités, a través de los servicios de extensión rural, impulsan la conformación de los 'grupos de amistad'. En palabras de Mejía (2003, p. 6), "esta estrategia se dirige a la familia y los grupos de vecindad próxima"; el objetivo fundamental fue el de "organizar y desarrollar una comunidad cafetera mediante la identificación de grupos de naturaleza informal constituidos por amigos o vecinos que interactúan con cierta frecuencia”.

Si bien la intencionalidad fue el optimizar recursos y potenciar la adopción colectiva de prácticas productivas para la mejora en la calidad del grano, esta apuesta institucional, por un lado, contribuyó al afianzamiento de las tramas comunitarias previamente existentes (reactualización); y, por otro, al intercambio de saberes. Una de nuestras entrevistadas recuerda que en el seno de estos grupos dialogaba sobre técnicas y conocimientos, los que procedían de los ajustes y adaptaciones que se hacían de las técnicas y conocimientos transferidos por las personas que realizaban los procesos de extensión rural.

Por otra parte, es de destacar que los grupos de amistad se constituyeron a su vez en espacios festivos. Los encuentros de productores se remataban con una fiesta o un juego de fútbol. Lo que es factible entrever es que las personas se apropiaron de un espacio institucional para hacer 'comunidad'. Este hacer no solo fue a través del intercambio de conocimientos, también con la instauración de espacios y momentos festivos, los que, para Gutiérrez (2017, p. 121), afianzan "las coaliciones y asociaciones centradas en el cuidado, celebración y producción de la vida”.

El tercer factor corresponde al trabajo desarrollado por la Iglesia católica, en cabeza del párroco Tiberio Fernández Mafla y del IMCA, y de organizaciones campesinas como la ANUC y la Fanal. Estas instancias tuvieron como objetivo el impulsar "un proyecto de desarrollo rural basado en la pequeña y mediana propiedad" cuyo eje sería el trabajo asociativo fundamentado en "valores de solidaridad" (CNRR, 2008, p. 95). Bajo esta lógica el acompañamiento se enfocó en que el campesinado construyese alternativas socioeconómicas para enfrentar de manera autónoma la debilidad institucional y los impactos de la crisis 
permanente de la producción y comercialización del café. También como espacios para el fortalecimiento político del campesinado.

Principalmente como resultado de la labor del padre Tiberio y del IMCA se constituyeron 45 empresas comunitarias, se impulsaron "grupos de la tercera edad, comités de cuadra y otras empresas familiares, entre las que se cuentan ebanisterías y panaderías" (CNMH, 2014, p. 184). El trabajo no solo apuntó a fortalecer alternativas económicas diferentes al cultivo del café (como la producción de mora materializada en empresas comunitarias como Asomora), también se enfocó en configurar redes sociales en torno a lo productivo. Así, el proceso cooperativo tuvo como eje "[...] un plan de trabajo pastoral que promovía el trabajo comunitario y asociativo entre la comunidad rural y urbana del municipio" (CNRR, 2008).

En algunas de las entrevistas se señaló que la conformación de cooperativas campesinas en la zona implicó dar un paso más en lo organizativo/comunitario campesino. En este sentido, estas cobraron protagonismo como espacios deliberativos y para la planificación de las acciones por seguir más allá de lo económico. El reconocerse como parte de un 'nosotros' cooperativo, la constitución de espacios de deliberación, decisión y agencia posibilitan "la creación y la reactualización de lo común” (Menéndez \& Noel Sosa, 2018, p. 186).

El proceso de cooperativización también debe ser aprehendido como un proceso de producción y también de reapropiación colectiva de la riqueza social. Primero, porque este implicó la desestructuración de relaciones productivas basadas en la explotación del campesinado; segundo, conllevó que colectivamente se definiese para qué y cómo producir (autonomía); y tercero, comportó la construcción de "una práctica económica centrada en dar prioridad al bienestar común” (Sabín, 2015, p. 37). Así la cooperativización en resumen fue una apuesta por "[...] hacerse con el control de los medios de producción y reproducción; que es la base para un proceso de sustracción respecto al capital y la construcción de la autonomía de la multitud” (Negri \& Hardt, 2011, p. 175). 


\section{El impacto del conflicto armado en la producción de lo común}

De acuerdo con las características que tomó el conflicto armado en la zona (actores, estrategias, dinámicas, territorialidad, entre otros), este se divide en momentos. El primero comprendido entre 1986 y 1994. Este lapso de tiempo enmarca lo que ha sido denominado como " $\mathrm{La}$ masacre de Trujillo". Desapariciones forzadas, torturas, homicidios selectivos, detenciones arbitrarias y masacres entretejieron una cadena de crímenes sistemáticos y generalizados, los que fueron perpetrados por una 'alianza regional y temporal' entre el narcotráfico, la Policía y el Ejército. El propósito de esta coalición "fue contrainsurgente" (CNRR, 2008, p. 37). En este contexto se concibe a los procesos comunitarios como actividades promovidas por la insurgencia (CNHM, 2014). Así, el asesinato del padre Tiberio Fernández y otras personas clave para la comunidad y la serie de violencias perpetradas contra la población civil apuntaron a desestructurar el tejido socioeconómico que se había ido entretejiendo con el apoyo de la Iglesia y otros actores. Este debilitamiento tenía como fin el que se crearan las condiciones para que el narcotráfico pudiese tener un mayor control sobre el territorio.

Un segundo momento se configura a partir de la llegada del Bloque Calima a la zona en 1998. Su arribo tuvo como empresa el contrarrestar el influjo territorial de las Fuerzas Armadas Revolucionarias de Colombia (FARC) y del Ejército de Liberación Nacional (ELN) (CNMH, 2008). Las acciones guerrilleras, durante el primer lustro de los noventa, limitaron la expansión del narcotráfico. Las insurgencias incrementaron las "acciones militares, las extorsiones y los secuestros, produciendo la reacción desmedida de narcotraficantes y algunos integrantes de las élites regionales" (CNMH, 2014, p. 218). Así la presencia de esta facción paramilitar en el municipio apuntaba a "garantizar el control del orden regional y el papel de élites ligadas a la economía legal, así como de empresarios criminales asociados a la economía del narcotráfico, librándolos del asedio y la amenaza guerrillera".

Como parte de su accionar el Bloque Calima desplegó una serie de repertorios de violencia contra el campesinado de La Sonora, 
El Tabor, las veredas Betulia y Maracaibo. La violencia extrema y el terror se usaron como tácticas de escarmiento y control social. Las acciones violentas se realizaron principalmente "en zonas en las que la guerrilla había avanzado en los últimos años y que representaban gran importancia para algunos empresarios y narcotraficantes" (CNMH, 2014, p. 260). Las masacres, desapariciones forzadas, desplazamientos, persecuciones, asesinatos selectivos, amenazas contra el campesinado buscaban en primera instancia "cortar los corredores construidos por la guerrilla" (p. 260); en segundo lugar, debilitar el apoyo social que el ELN tenía entre el campesinado organizado, y además promover la desocupación de tierras, con el fin de favorecer la posterior adquisición por parte de Smurfit Cartón Colombia.

Con la presencia paramilitar se establece un mayor control territorial. Los miembros de esta estructura criminal se posicionaron en la zona, imponiendo normas y regulaciones a través de la violencia física y simbólica. Si bien el control territorial se manifiesta directamente con el control de las vías que sirve de rutas para el tráfico de drogas y de armas o para el avance de las tropas, en el caso que nos atañe, este abarcaba una serie de mecanismos de intervención de la vida cotidiana de la gente. Los aspectos mencionados son corroborados por una de las entrevistas: "Lo que se vivió con los paras fue tremendo, porque aquí, aquí mantenían un retén, en todos estos caseríos ellos mantenían un retén, y controlaban quién entraba y quién salía, controlaban qué hacíamos. Ellos sabían quién venía, quién se iba, qué hacíamos en las casas y prohibían los encuentros" (comunicación personal, La Sonora, 2019).

La tercera etapa correspondió con la desmovilización del Bloque Calima en 2004 y la ocupación del territorio por parte de Los Rastrojos entre 2005 y 2012. El objetivo fue el control territorial, principalmente de los circuitos de tráfico de drogas (UARIV, 2014). La desmovilización de las AUC implicó la "redefinición del control territorial por medio de la violencia” (CNMH, 2014). Un gran número de miembros del Bloque Calima que 'supuestamente' se desmovilizaron confluyeron en las Bacrim. Específicamente en la zona de 
La Sonora operaron Los Rastrojos. ${ }^{11}$ El objetivo principal de este grupo fue el "copar los espacios dejados por los paramilitares y controlar los circuitos productivos legales e ilegales, consolidar una base social, así como escenarios de reconocimiento y legitimización social y política" (CNMH, 2014, p. 298). Los Rastrojos retomaron el control de la carretera que cruza las veredas de El Tabor y La Sonora.

El conflicto armado afectó profundamente los procesos comunitarios. La CNRR (2008, p. 14) establece que en Trujillo las acciones violentas de los armados apuntaron a "someter, desplazar y eliminar a determinados sectores de la población, o de una determinada colectividad" (p. 16). Una parte importante de las víctimas de esta zona estaban vinculados, directa o indirectamente, a alguno de los procesos organizativos y comunitarios del territorio. Así, en este contexto se victimizó a personas que jugaron un importante papel en el "engranaje de la vida cotidiana" o que "actuaban como nodos de articulación de las redes sociales comunitarias” (p. 80). Líderes, parteras, enfermeras, miembros de las cooperativas, de los grupos de amistad, los transportistas, cualquiera que tuviera relación con las redes socioeconómicas se constituyó en potencial víctima de los armados.

En este contexto, "las organizaciones promovidas por la Iglesia, como otras surgidas en el seno del trabajo agenciado por Fanal, la ANUC y las mismas juntas de acción comunal, generadas por la institucionalidad nacional, se fueron debilitando, desapareciendo progresivamente" (CNRR, 2008, p. 140). La asociación que se hizo de estas con la subversión las posicionó como objetivo militar de los actores armados. Muchas de las personas vinculadas a estos procesos tuvieron que abandonar el territorio debido a la serie de amenazas de las que fueron víctimas; otros fueron desaparecidos y asesinados.

\footnotetext{
11 Este grupo es un ejército compuesto por exparamilitares al servicio del narcotraficante Wilber Varela. Con la llegada y posicionamiento de este grupo en la zona se dio una nueva oleada de violencias contra la población civil.
} 
Las violencias perpetradas por los armados en los diferentes momentos socavaron los cotidianos esfuerzos por sostener material y simbólicamente la reproducción de la vida social. Las tramas comunitarias se desestructuraron. Esto comprometió la centralidad que valores como el respeto, la colaboración y la reciprocidad habían ganado. También se desestabilizaron los saberes y capacidades colectivas que el cooperativismo, por ejemplo, generó. Las violencias alteraron la relación de la comunidad campesina con su entorno inmediato, limitaron el acceso y uso de los recursos comunales y de la infraestructura pública y colectiva que se había construido bajo el influjo del Comité de Cafeteros. Además, se limitaron los encuentros, desapareció el trabajo colectivo (en algunos casos las personas fueron obligadas a trabajar en la carretera o en alguna finca por orden de los paramilitares) y los espacios festivos se acabaron. Emergió el miedo y la desconfianza dentro de la comunidad; este aspecto incidió negativamente en lo comunal, pues fue reconocido en varias de las entrevistas como un factor que limitó el encuentro y el trabajo colectivo.

Con respecto a las violencias y sus efectos en lo colectivo en el marco de la Resolución 446985, se destaca, en primer lugar, la particularidad de las violencias del conflicto y de los impactos en cuanto a las características del territorio, estableciéndose que al ser montañosa la zona se ha constituido históricamente en lugar de retaguardia de los armados; por otra parte, se señala que la vía que atraviesa los corregimientos y las veredas tiene comunicación con el Pacífico vallecaucano, aspecto que facilitó el tráfico de drogas y armas y la movilización de los armados. El control del territorio implicó el control de la vida cotidiana de los habitantes. En segundo lugar, se resalta cómo el asesinato de líderes comunitarios y la relación de este hecho con el debilitamiento del tejido comunitario resultó clave para el control territorial por parte de los armados. En tercer lugar, se plantea que las masacres, desapariciones forzadas, desplazamientos, persecuciones, asesinatos selectivos, amenazas contra el campesinado apuntaban a limitar la movilidad de las guerrillas y a bloquear los esfuerzos organizativos comunitarios estructurados en la década de los ochenta por parte de los campesinos y la Iglesia. En cuarto lugar, se habla sobre 
la conexión entre las dinámicas de la guerra y la modificación de los patrones productivos en la zona.

\section{Tomando conciencia del daño colectivo}

Tal como se estableció en anteriores apartes, el reconocimiento del sujeto de reparación colectiva de La Sonora se produce en 2014. En el marco del Decreto 4800 de 2011, en el artículo 227 se establece que este procederá a través de dos vías: oferta ${ }^{12}$ o demanda. ${ }^{13}$ En el caso de La Sonora, este se hizo por oferta. En enero de 2013, la UARIV sede Valle del Cauca seleccionó el caso como un posible sujeto de reparación colectiva. Para dar inicio al proceso esta instancia visitó la zona y realizó una breve reconstrucción de las victimizaciones con personas clave de la comunidad; además, procedió a identificar preliminarmente los impactos del conflicto armado en la dimensión colectiva.

Posterior al reconocimiento, se llevó a cabo la etapa de "alistamiento". ${ }^{14}$ Durante esta fase se crearon los comités de impulso y Entrelazando. ${ }^{15}$ En cuanto al primero, se conformó con un número representativo de personas de la comunidad, quienes asumieron la responsabilidad de "estimular la participación en el proceso e interlocutar con la UARIV, representar a los miembros del sujeto de reparación colectiva, consultándoles sobre cada decisión a tomar, socializar los avances y retrocesos y recolectar la información necesaria para la construcción de la memoria del proceso" (comunicación personal, La Sonora, 2018).

\footnotetext{
12 La UARIV determina si un colectivo puede ser un sujeto de reparación colectiva a través de la recopilación de insumos por medio de las fuentes especificadas por el mencionado y procede a contactar al colectivo con el fin de iniciar el proceso.

13 Esta procede cuando el sujeto colectivo realiza la solicitud ante la UARIV. En ese caso, la Unidad valora el caso y decide si incluirlo o no en el Registro Único de Víctimas.

14 Es durante esta que se prepara "al sujeto de reparación colectiva y a las entidades de orden territorial y nacional, así como a las instituciones privadas interesadas" para su participación en el proceso" (UARIV, 2018, p. 60). Este tiene una doble dimensión: comunitaria e institucional.

15 Esta estrategia está dirigida a identificar y atender los daños psicosociales colectivos generando acciones para "la reconstrucción del tejido social y organizativo" (UARIV, 2018, p. 91).
} 
El Comité Entrelazando se constituyó en el dispositivo para materializar la estrategia de reconstrucción social Entrelazando. ${ }^{16}$ Fue conformado por las personas que la comunidad identificó con la capacidad de contribuir a la reconstrucción del tejido comunitario y a la recuperación de las redes sociales y la confianza entre los miembros del colectivo. A estas personas se las denomina como "tejedoras comunitarias", dado que fungen como "cuidadores de sus comunidades que ayudan a mantener la estabilidad emocional de las mismas en momentos de crisis, ya que ellos y ellas han vivido todo el conflicto y postconflicto en su misma comunidad" (Ordóñez et al., 2017, p. 35). Estas personas pasaron por un proceso de formación, que fue guiado y acompañado por la UARIV. Este se enfocó en dotarlas de las habilidades para: 1) acompañar a la comunidad en la elaboración de 'duelos colectivos'; 2) desarrollar prácticas sociales encaminadas a la reconstitución del tejido social y la confianza; 3) estimular la construcción de imaginarios colectivos que sirvan de soporte a la reconciliación y la construcción de la paz (León, 2018).

Este programa ha sido de vital importancia en la reconstrucción de la confianza, la que fue debilitada en el contexto de las violencias desplegadas por los armados. Al respecto varias de las personas que fueron entrevistadas manifestaron: "Fue tan fuerte ese rompimiento del tejido social que llegó a partes donde yo por muy amiga que usted fuera mía, yo desconfiaba de usted", "Con todo lo de los grupos al margen de la ley así yo no estuviera implicado, me llegaba cualquiera que fuera y yo dudaba", "Ni le da por visitar, ni siquiera por tener relaciones con otras personas, porque uno vivía arisco" (comunicaciones personales, La Sonora, 2018). Frente a los efectos de la puesta en marcha de este comité, las personas entrevistadas reconocieron: "El programa y el comité y los entrelazadores han logrado que la confianza vuelva, que nos veamos como comunidad, que no nos veamos como enemigos o que el otro me va a hacer daño", "Lo que hacemos es tejer, somos tejedores, tejemos confianza entre quienes vivimos aquí, tejemos comunidad, tejemos familia, vamos urdiendo,

\footnotetext{
16 Esta "contempla la reconstrucción del tejido social a partir del fortalecimiento en la convivencia comunitaria” (Ordóñez et al., 2017).
} 
con lo que hacemos de nuevo lo comunitario" (comunicaciones personales, La Sonora, 2019).

Posteriormente se efectuó el diagnóstico del daño. Mediante un proceso participativo identificaron los daños colectivos, "su magnitud y su vigencia en el sujeto colectivo, de manera que las medidas de reparación respondan a esos daños" (UARIV, 2018). La construcción del diagnóstico gira alrededor del daño colectivo. Este es entendido como las "afectaciones negativas en el contexto social, comunitario o cultural que, a causa del conflicto armado, sufren las comunidades, grupos u organizaciones y que tienen formas vigentes de sufrimiento o afectación” (UARIV, 2014, p. 16). Este se inició con la reconstrucción de los hechos de violencia y se identificó la centralidad de las afectaciones en el tejido social y comunitario. Quienes participaron señalaron los impactos de las acciones armadas en los procesos impulsados por el padre Tiberio y el IMCA. Además, destacaron cómo la guerra acabó con las formas de trabajo colectivo y de solidaridad que existían en el territorio, manifestando, por ejemplo, que "paras, guerrillas, ejército y los delincuentes de las Bacrim lo que no querían es que lo comunitario esté, lo quisieron acabar para controlar mejor el territorio", "La gente sin unión quedó, la gente no quería reunirse ni hacer nada comunitario, tenían miedo y desconfianza", "Los que se fueron pues ya nada de lo comunitario les importaba y los que nos quedamos miedo teníamos" (comunicaciones personales, La Sonora, 2019).

Por otra parte, se resaltó el impacto de la estigmatización en los procesos comunitarios. En varias de las entrevistas se manifestó: "Empezamos a ver cómo nos veían los de afuera, nos veían como guerrilleros", "Nos tildaban de ciertas cosas que no queríamos", "Dejaron de vernos como campesinos trabajadores, personas de bien y nos veían como si fuéramos de algún grupo armado", "No éramos una comunidad, nos veían como personas que tenían vínculos con los armados" (comunicaciones personales, 8 de septiembre de 2018). En este sentido, en el ejercicio de construcción de la matriz del daño, se postuló la estigmatización como uno de los daños más graves, estableciéndose que esta implicó un proceso de atomización 
de los referentes identitarios colectivos basados en la pertenencia a un territorio o por la historia y las tradiciones compartidas.

La información recabada fue recogida en la matriz del daño, ${ }^{17}$ en el marco de la cual se establecieron un total de quince acciones encaminadas a la reconstrucción de la dimensión colectiva de los habitantes de La Sonora, El Tabor, Betulia y Maracaibo. Esta sirvió como insumo para la construcción del PIRC. ${ }^{18}$ Enmarcada en la medida de 'restitución', los miembros del SRCT definieron como acciones, entre otras: ${ }^{19}$ "Recuperar la capacidad económica y productiva" y "recuperar y fortalecer las dinámicas comunitarias y los espacios de encuentro". Con la finalidad de materializar estas apuestas se crea Cimevat. Estrategias mediante las que se apunta a recuperar las formas de organización campesina y comunitaria debilitadas por el conflicto.

\section{Cimevat como condiciones de posibilidad del hacer}

Según consta en sus estatutos (s. f.), el objetivo de la cooperativa es asegurar el "desarrollo y progreso económico [...], social y cultural" de sus miembros, "utilizando para ello la producción, la transformación, la distribución, la comercialización y mercadeo de bienes y prestación de servicios [agrícolas] a sus asociados y a la comunidad en general", con base en los principios del cooperativismo. Cimevat se dedica principalmente a la producción y comercialización del café — principal cultivo del municipio_ y en menor medida de frutales como la mora, el tomate de árbol y los cítricos.

\footnotetext{
17 La matriz del daño del SRCT consta de siete medidas, entre las cuales se encuentran acciones de restitución, rehabilitación, satisfacción y garantías de no repetición.

18 El Plan Integral de Reparación Colectiva "es un instrumento de planeación que define y programa la implementación de las acciones dirigidas a reparar los daños ocasionados a los atributos del colectivo, en el marco del conflicto armado" (UARIV, 2018, p. 74).

19 Otras de las medidas establecidas fueron: superar las afectaciones físicas y psicológicas resultado del conflicto armado (rehabilitación), recuperar el buen nombre y la identidad comunitaria, celebración anual de las fiestas del retorno (satisfacción), acceso a información sobre hechos de desaparición forzada (garantías de no repetición) (matriz del daño, SRCT).
} 
La conformación de la cooperativa en 2015 fue un proceso viabilizado por la conjunción de seis factores: 1) el clima de paz instaurado en el contexto de las negociaciones de paz, escenario que facilitó el retorno de quienes fueron víctimas de desplazamiento forzado; 2) el apoyo técnico y financiero recibido de instancias estatales (UARIV, Ministerio del Trabajo, Sena) y no estatales (universidades, IMCA, Iglesia católica); 3) la latencia de vínculos sociales y comunitarios ("Nosotros nos vimos crecer, nosotros éramos como familia"), del ethos comunal y la recuperación de la confianza ("Nos hemos vuelto a dar esa confianza"); 4) la herencia asociativa y de cooperativismo dejada por Tiberio y mantenida por el IMCA; 5) las experiencias y aprendizajes en el marco de los diversos procesos de justicia transicional que se han desarrollado en el territorio; y 6) la conformación previa de asociaciones de víctimas.

La idea de crear una asociación se venía gestando en la comunidad desde el inicio del proceso de reparación colectiva. Esto se pensó en principio como una estrategia para garantizar la sostenibilidad del proceso, tal como lo narra una de las personas entrevistadas:

Cuando iniciamos decíamos que todo este trabajo no vaya a ser en vano. Que haya algo que quede como un fruto de todo esto y todas estas reuniones o algo así. Le decíamos a la gente de la UARIV, ustedes salen y se van y quedamos por las mismas, entonces yo hacía mucho tiempo venía pues con la idea de una asociación aquí en la vereda porque el sitio donde realmente fueron los hechos es aquí, es donde realmente se despierta todo lo que se empezó a construir, entonces yo dije pues una parte donde realmente fue más afectada y todo eso y no hay siquiera una asociación [...] (comunicación personal, 8 de septiembre de 2018).

El proyecto de asociarse alrededor de una cooperativa se gesta en el seno del Comité Entrelazando. Quienes participaban en este espacio realizaron un ejercicio reflexivo en torno a la funcionalidad de crear un lugar organizativo como mecanismo, para reconstituir lo comunitario, para tejerlo y, por supuesto, para la reactivación productiva de los habitantes de la zona. En armonía con esta iniciativa, la UARIV 
insta a los participantes del proceso a que consideren esta posibilidad, dado que, para el desarrollo de otras de las acciones amarradas al PIRC, resulta clave una organización con personería jurídica.

En 2016 Cimevat se vincula al proyecto Sumando Paz, ${ }^{20}$ el que fue desarrollado en alianza entre el Ministerio del Trabajo y la Organización Iberoamericana de la Seguridad Social (OISS). En el marco de este proceso, se organizaron una serie de actividades para el fortalecimiento de la producción de café, considerando esta actividad como eje de las dinámicas económicas en el territorio. En esta vía se planteó que el fortalecimiento productivo redundaría en la recomposición del tejido social. En esta misma vía operó en los años ochenta el padre Tiberio y el IMCA. Así, la cooperativa es una estrategia para recomponer la capacidad económica de las familias y crear y fortalecer los lazos comunitarios.

Con respecto a la producción de lo común, proponemos considerar el proceso en las siguientes dimensiones:

\section{- Un lugar comunitario para la reconstitución de la confianza.}

La creación de Cimevat es considerada por sus miembros como un paso para la construcción mutua de confianza. Frente a este aspecto, en uno de los talleres realizados en la zona, quienes participaron manifestaron que, previo al inicio, el miedo y la desconfianza obstaculizaban la posibilidad de rehacerse como colectivo. Así la cooperativa supuso un arduo trabajo por parte de sus miembros para poder confiar en el otro. Ese poder confiar en el otro, que paulatinamente se ha ido materializando, está posibilitando el autorreconocimiento de la cooperativa como un nosotros.

\footnotetext{
20 Este proyecto tuvo como finalidad el "realizar acciones orientadas a la restitución de derechos de 23 sujetos de reparación colectiva (SRC), a través de procesos de fortalecimiento o conformación de organizaciones sociales y asociativas lideradas por las víctimas del conflicto armado que contribuyan a la reconstrucción del tejido social y sus territorios" (Ministerio del Trabajo \& OIss, 2018, p. 5).
} 
- La recomposición de las tramas comunitarias. Bajo la perspectiva de esta investigación, este proceso está operando en la recomposición y composición de tramas comunitarias en la medida en que está permitiendo la reactualización de las tramas preexistentes, a la vez que posibilita la emergencia de nuevos vínculos comunitarios. $\mathrm{Al}$ respecto, en varias de las entrevistas se manifestó lo siguiente: "La cooperativa ha sido un ejercicio sobre todo para volvernos a reconocer y para darnos cuenta que estábamos los que siempre habíamos estado", "Cuando la guerra se fue la gente volvió y se pudo volver a ser amigos, familia, comunidad. También llegó gente nueva que se ha quedado o que viene y va, y con ellos también nos vamos reconociendo", "Acá somos familia, sino es familia de sangre es familia de corazón. La guerra nos quitó eso, pero ya lo hemos vuelto a tener" (comunicaciones personales, La Sonora, 2018). En este sentido la reparación colectiva contribuye a forjar la cohesión social. A raíz de los procesos organizativos generados por el proceso de reparación colectiva es que las personas han vuelto a sentirse parte de una comunidad, parte de lo comunitario, de un colectivo, estableciendo que estos procesos han contribuido a la cohesión social de los miembros de la cooperativa y de la comunidad en general: "Hoy en día ver todas esas familias como congregadas ahí y que a veces nos sentimos como familia, en recocha y como con una buena amistad, yo creo que eso es de valorar, porque si no hubiera sido por esto no estuviéramos en el paso que hemos estado y sí hay muchos eventos donde nos hemos sentido muy bueno" (comunicación personal, 8 de septiembre de 2018).

\section{- La asamblea como un escenario para la toma de decisiones.}

Otro aspecto que debemos señalar es la existencia de espacios asamblearios, reglas y participación de la mayor parte de los miembros de la cooperativa. Esta se encuentra (hoy) conformada por 70 familias (socios). Organizativamente hablando está dividida en varios subcomités: de trabajo comunitario (regular y promover formas de trabajo comunitario como la minga y el convite); manejo de la planta de procesamiento de café (incluido el camión); contable; vida comunitaria; y de gobierno. Cada uno de estos cumple con una función específica, 
la que se considera clave para el buen funcionamiento de la cooperativa. En el de gobierno confluyen: representantes de cada uno de los subcomités con la tesorera, secretario y representante legal. Este funge como enlace de todos los comités, además de constituirse en la figura en la que recarga la representatividad ante las instancias estatales y no gubernamentales.

Las reuniones de la cooperativa son mensuales (espacio asambleario) con el objetivo de revisar los avances sobre las tareas asignadas y acuerdos, discutir sobre temas relevantes para la cooperativa, tomar decisiones, entre otros. Los representantes de los subcomités se encuentran previo a la reunión mensual para concretar sobre los avances o hablar sobre algún tema que deba ser considerado prioritariamente en el seno de la asamblea.

Para la toma de decisiones, cada representante de los subcomités expone ante todos el asunto que debe ser debatido, presentando el tipo de decisión que debería ser votada. Es durante este espacio que el resto de los miembros puede aportar a la reflexión sobre el asunto y la decisión. Posterior a la socialización se abre la votación colectiva. Cada familia (socio) tiene derecho a votar. La decisión se toma si por lo menos un $60 \%$ de quienes asisten están de acuerdo. La materialización estará a cargo del comité al que le corresponda el tema y el de gobierno, instancia que apoyará y realizará el seguimiento.

Como todo proceso, este no está libre de tensiones, pugnas y desigualdades. Es de destacar que si bien en los comités hacen presencia activa las mujeres, en la toma de decisiones son los hombres quienes mayormente la ejercen. Esto tiene que ver con el orden tradicional de género, marco bajo el cual no se concibe a las mujeres con igual poder de decisión que el de los varones, aun cuando ellas son quienes más dan vida al colectivo. Al respecto en varias de las entrevistas se manifiesta: "En cada comité están mujeres que trabajan duro para que la cooperativa salga adelante, pero no las dejan opinar", "Con este proceso me he empoderado, pero es duro, duro, hay mucho machismo", "A algunas mujeres los maridos no las dejan participar y 
a las reuniones van los esposos o los hijos mayores" (comunicaciones personales, El Tabor, 2019).

Sin embargo, muchas de las socias reconocen que el espacio que se ha abierto con la cooperativa y con otros de los procesos anclados a la reparación colectiva les ha permitido empoderarse. Reconocen cambios sustanciales en su comportamiento y en sus vidas como resultado de la participación activa en los procesos. También la cooperativa se ha constituido en un espacio de cuidado y de defensa. La solidaridad de género emerge en situaciones de violencia y las mujeres socias han tejido redes de afecto y solidaridad entre ellas, las que les permiten sortear las complejas violencias patriarcales: " $\mathrm{Ha}$ sido una lucha, porque no es fácil, a algunas les han prohibido participar o las callan en las reuniones, pero con esto hemos construido afectos que nos protegen" (comunicación personal, El Tabor, 2019).

En cuanto a los aportes monetarios que hacen los socios a la cooperativa (20000 pesos mensuales), una parte (30\%) se deja para el mantenimiento básico de la asociación y el $70 \%$ es ahorrado. En caso de necesidad, el dinero puede ser prestado (sin intereses) a algún miembro que lo necesite de manera urgente o para cubrir solidariamente gastos en los que no puedan incurrir, como, por ejemplo, un entierro.

- La producción de la riqueza social. En cuanto a la producción y reproducción de la riqueza social, con el apoyo del Ministerio del Trabajo y Funpaz, y en el marco del convenio Sumando Paz, se dictaron una serie de capacitaciones a los miembros del sujeto de reparación colectiva en cooperativismo y diseño y gestión de proyectos productivos. En este contexto se identificó como prioritario el desarrollo de proyectos para la transformación y comercialización del café, dado que es la actividad económica que históricamente ha contribuido a la supervivencia de las familias de la zona.

A través de la suma de los esfuerzos técnicos, administrativos y financieros entre la UARIV y el Ministerio de Trabajo, con las acciones comunitarias de gestión y trabajo colectivo de los miembros de la comunidad, se ha dado impulso a este proyecto: transformación 
y comercialización de cafés especiales, ${ }^{21}$ el que actualmente es eje de las dinámicas de la cooperativa. El proyecto no solo ha permitido que las personas reafirmen los lazos comunitarios necesarios para darle impulso, también se da en la cotidianidad el intercambio de saberes y conocimientos acerca de la producción y procesamiento del café, a la vez que en conjunto construyen estrategias para su comercialización.

Si bien existe interés en que el proceso productivo redunde en beneficios económicos para cada asociado/a, la apuesta principal es que las ganancias económicas del proceso contribuyan a mejorar el nivel de vida de los cooperativistas y de la comunidad en general. Aspiran a que en el mediano plazo el resto de las personas, no solamente quienes pertenecen al sujeto de reparación colectiva sobre el que versó este estudio, se sumen al proceso, consolidándose la producción y comercialización de cafés especiales en eje de desarrollo de la zona.

- Centralidad del trabajo colectivo. Otro aspecto por destacar es que la cooperativa ha contribuido a la recuperación de prácticas de trabajo colectivo como, por ejemplo, el convite y las mingas. En el marco del trabajo de campo tuvimos la oportunidad de asistir al primer convite realizado por Cimevat. Este tuvo como objetivo adecuar el lugar en el que guardan el camión que les fue dado como parte de las medidas de reparación. La cooperativa como un espacio de encuentro ha propiciado una revaloración de estas prácticas: "Convites, mingas, todo eso se había perdido, ahora con Cimevat es que las estamos recuperando, porque son necesarias, si no trabajamos todos por todos esto no funcionará. Más que plata para que funcione este proyecto lo que se necesita es que pongamos trabajo" (comunicación personal, Betulia, 2018).

\footnotetext{
21 Para el desarrollo de este, el Ministerio dotó a la comunidad de: equipos para el procesamiento industrial del café (secadora, tostadora, trilladora). La UARIV hizo la entrega de una camioneta para el transporte y comercialización del producto. El Sena y actores no gubernamentales se han sumado al proceso a través de procesos formativos sobre cooperativismo y economía solidaria.
} 
- La resignificación de lo colectivo. Con las violencias la red de apoyo comunitaria había quedado desmantelada. El impacto en el tejido social se hizo notorio en la falta de solidaridad y de confianza, aspectos que limitaban el establecimiento de apuestas comunes. La comunidad menciona que, a medida que se desarrollaba el proceso de reparación colectiva, se fue reconstruyendo ese 'volver a creer' en lo colectivo. Frente a este aspecto, las personas han manifestado: "Retomamos esas ganas de querer transformarlo, de querer unirnos nuevamente", "En este proceso es que hemos creído que sí es posible recuperar ese vínculo de comunidades de volver a creer, de trabajar en equipo" (comunicaciones personales, 8 de septiembre de 2018). En este contexto, han surgido propuestas de autoprotección, de prevención, de apropiación de su territorio. Algunos participantes del proceso le han dado gran importancia a generar garantías de no repetición y se señalan propuestas para prevenir los hechos violentos; para unir fuerzas a fin de que se preserve la paz en su territorio.

\section{Conclusiones}

La reparación colectiva a nuestro modo de ver está 'posibilitando el hacer'. Esto en la medida en que, por su misma naturaleza (colectiva), reactualiza o "producen nuevas formas de cooperación, recuperando, conservando y transformando las tradiciones locales en las cuales quienes luchan han sido formados y de donde casi siempre brotan sus capacidades tanto de creación como de insubordinación; adecuándolas, expandiéndolas o perfeccionándolas para los propósitos que persiguen" (Gutiérrez, 2017, p. 31).

En este sentido, está dando lugar a la ruptura y configuración de nuevas realidades sociales como resultado de la resignificación y negociación por parte de la comunidad. Al apropiarse de estos mecanismos en su cotidianidad se propician actividades concretas, comunitarias destinadas, en el sentido de Gutiérrez (2017), a garantizar la reproducción material y simbólica de la vida social. 
Gracias a los esfuerzos cotidianos colectivos para recobrar la confianza y retejer la comunidad es que se pudo ensayar este formato asociativo o de cooperación que es Cimevat. Aquí se gestan encuentros estructurados cara a cara que dan lugar a una 'comunidad de sentido'. Con estas prácticas desde el hacer cotidiano es que las personas han percibido el potencial de la supervivencia colectiva.

En este sentido y en un escenario transicional, la comunidad está avanzado (también con dificultades) en un camino hacia la autonomía, la producción de riqueza, conocimiento y cooperación. Con la apuesta central puesta en la producción de café se han enriquecido dinámicas asociativas con el objetivo de reproducir colectivamente la vida desde los haceres cotidianos, siempre en confrontación silenciosa con el pasado de despojos que amenazan continuamente con volver.

\section{Referencias}

Caffentzis, G., \& Federici, S. (2015). Comunes contra y más allá del capitalismo. El Apantle: Revista de Estudios Comunitarios, (1), 51-72.

CNMH. (2008). Trujillo: una tragedia que no cesa. Bogotá: Planeta.

CNMH. (2014). "Patrones" y campesinos: tierra, poder y violencia en el Valle del Cauca (1960-2012). CNMH.

Colombia, Congreso de la República. (2011). Decreto 4800 de 2011. Recuperado de http://www.unidadvictimas.gov.co/sites/default/files/ documentosbiblioteca/decreto-4800-de-2011.pdf

Colombia, Congreso de la República. (2011). Ley 1448 de 2011. Recuperado de http://www.unidadvictimas.gov.co/sites/default/files/documentosbiblioteca/decreto-4800-de-2011.pdf

Cordero, B. (2018). Trabajo vivo, hacer y producción de lo común: notas para ampliar diálogos entre tradiciones. En R. Gutiérrez Aguilar (Coord.), Comunalidad, tramas comunitarias y producción de lo común. Debates contemporáneos desde América Latina. Colectivo Editorial Pez en el Árbol-Editorial Casa de las Preguntas.

De Angelis, M. (2003). Reflections on alternatives, commons and communities or building a new world from the bottom up. The Commoner, 1-14. 
Esteba, G., \& Guerrero, A. (2018). Usos, ideas y perspectivas de la comunalidad. En R. Gutiérrez Aguilar (Coord.), Comunalidad, tramas comunitarias y producción de lo común. Debates contemporáneos desde América Latina. Colectivo Editorial Pez en el Árbol-Editorial Casa de las Preguntas.

Gutiérrez, R., Navarro, L., \& Linsalata, L. (2016). Repensar lo político, pensar lo común. Claves para la discusión. En D. Inclán, L. Linsalata \& M. Millán, Modernidades alternativas. Ediciones del Lirio.

Gutiérrez, R. (2017). Horizontes comunitario-populares: producción de lo común más allá de las políticas Estado-céntricas. Traficantes de Sueños.

Gutiérrez, R. (2018). Producir lo común: entramados comunitarios y formas de lo político. En R. Gutiérrez Aguilar (Coord.), Comunalidad, tramas comunitarias y producción de lo común. Debates contemporáneos desde América Latina. Colectivo Editorial Pez en el Árbol-Editorial Casa de las Preguntas.

Gutiérrez, R., \& Salazar, H. (2015). Reproducción comunitaria de la vida. Pensando la transformación social en el presente. El Apantle. Revista de Estudios Comunitarios, (1), 15-50.

Holloway, J. (2011). Agrietar el capitalismo. El hacer contra el trabajo. Herramienta Ediciones.

León, S. (2018). Transformaciones y tensiones de los procesos de reparación colectiva: el caso de Trujillo (Trabajo de grado, Pontificia Universidad Javeriana, Bogotá).

Linsalata, L. (2015). Cuando manda la asamblea. Lo comunitario-popular en Bolivia: una mirada desde los sistemas comunitarios de agua de Cochabamba. SOCEEAutodeterminación-Fundación Abril.

Menéndez, M., \& Noel Sosa, M. (2018). Cooperativismo de vivienda en Uruguay: lo común como práctica educativa. En R. Gutiérrez Aguilar (Coord.), Comunalidad, tramas comunitarias y producción de lo común. Debates contemporáneos desde América Latina. Colectivo Editorial Pez en el ÁrbolEditorial Casa de las Preguntas.

Navarro, M. L. (2013). Lucha por lo común contra el renovado cercamiento de bienes naturales en México. Bajo el Volcán, 13(21), 161-169.

Negri, A., \& Hardt, M. (2011). Commonwealth el proyecto de una revolución del común. Ediciones Akal.

Ordóñez Mariño, M. de los Á., Moncada González, D. I., Restrepo Sánchez, S. J., \& Cortés Rojas, N. (2017). La participación, camino para la reparación colectiva. Para tejer territorios de pa:. Universidad de La Salle. 
Sañudo, M. F., Quiñones, A. J., Copete, J. D., Díaz, J. R., Vargas, N., \& Cáceres, A. (2016). Extractivismo, conflictos y defensa del territorio: el caso del corregimiento de La Toma (Cauca-Colombia). Desafíos, 28(2), 367-409. https:/ / doi.org/10.12804/desafios28.2.2016.10

Sañudo, M., \& Aguilar, D. (2018). Historias de despojo y resistencias: los retos comunes. Cartilla pedagógica. Instituto Pensar, PUJ.

Svampa, M., \& Viale, E. (2014). Maldesarrollo. La Argentina del extractivismo y el despojo. Katz.

UARIV. (2014). Resolución 2014-446985 del 5 de mayo de 2014.

UARIV. (2018). Modelo de reparación colectiva. Bogotá. Recuperado de https:/ / www.unidadvictimas.gov.co/sites/default/files/documentosbiblioteca/libromrcdigitalold.pdf

Vega, C. (2019). Reproducción social y cuidados en la reinvención de lo común. Aportes conceptuales y analíticos desde los feminismos. Revista de Estudios Sociales, (70), 49-63.

Zibechi, R. (2015). Los trabajos colectivos como bienes comunes material/ simbólicos. El Apantle. Revista de Estudios Comunitarios, (1), 73-97. 